3-12-2019

\title{
Protecting women and children in conflict settings
}

\author{
Zulfiqar Ahmed Bhutta \\ The Aga Khan University, zulfiqar.bhutta@aku.edu \\ Michelle F. Gaffey \\ Aga Khan University \\ Karl Blanchet \\ London School of Hygiene and Tropical Medicine, London \\ Ron Waldman \\ George Washington University, Washington DC. \\ Kamran Abbasi \\ The BMJ, London, UK.
}

Follow this and additional works at: https://ecommons.aku.edu/

pakistan_fhs_mc_women_childhealth_paediatr

Part of the Pediatrics Commons

\section{Recommended Citation}

Bhutta, Z. A., Gaffey, M. F., Blanchet, K., Waldman, R., Abbasi, K. (2019). Protecting women and children in conflict settings. British Medical Journal, 364, 11095.

Available at: https://ecommons.aku.edu/pakistan_fhs_mc_women_childhealth_paediatr/766 


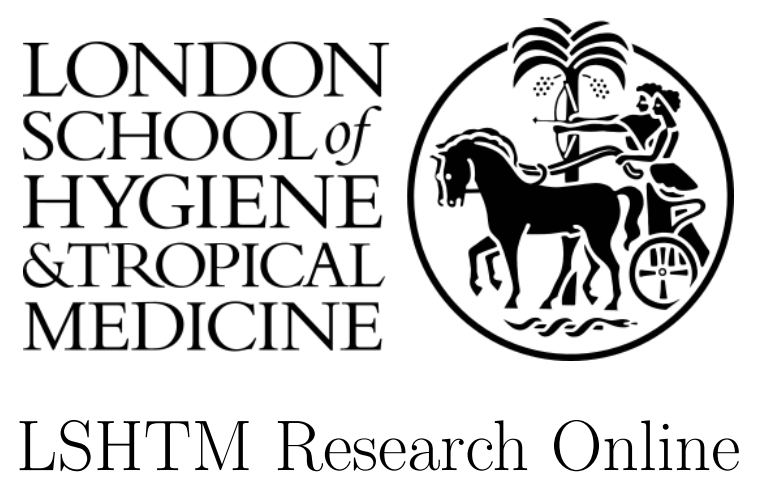

Bhutta, Zulfiqar A; Gaffey, Michelle F; Blanchet, Karl; Waldman, Ron; Abbasi, Kamran; (2019) Protecting women and children in conflict settings. BMJ, 364. 11095-11095. ISSN 0959-8138 DOI: https://doi.org/10.1136/bmj.11095

Downloaded from: http://researchonline.lshtm.ac.uk/4652507/

DOI: https://doi.org/10.1136/bmj.11095

\section{Usage Guidelines:}

Please refer to usage guidelines at https://researchonline.lshtm.ac.uk/policies.html or alternatively contact researchonline@lshtm.ac.uk.

Available under license: http://creativecommons.org/licenses/by/2.5/ 


\title{
Protecting women and children in conflict settings
}

\author{
Children and their families urgently need better evidence, better care, and better outcomes
}

\author{
Zulfiqar A Bhutta professor ${ }^{12}$, Michelle F Gaffey senior research manager ${ }^{1}$, Karl Blanchet director ${ }^{3}$, \\ Ron Waldman professor ${ }^{4}$, Kamran Abbasi executive editor ${ }^{5}$ \\ ${ }^{1}$ Centre for Global Child Health, Hospital for Sick Children, Toronto, Canada; ${ }^{2}$ Center of Excellence in Women and Child Health, Aga Khan University, \\ Karachi, Pakistan; ${ }^{3}$ Health in Humanitarian Crises Centre, London School of Hygiene and Tropical Medicine, London, UK; ${ }^{4}$ Milken Institute School \\ of Public Health, George Washington University, Washington DC, USA; ${ }^{5}$ The BMJ, London, UK
}

A recent Save the Children report highlighted that some 357 million children, one in every six children in the world, currently live in a conflict zone. ${ }^{1}$ Almost half of them live in severe conflict settings. Wagner et al $^{2}$ estimate that a child born within $50 \mathrm{~km}$ of an armed conflict event in Africa has a $7.7 \%$ excess risk of dying in infancy. This equates to 5.2 more deaths per 1000 births than during periods without conflict in the same region (95\% confidence interval 3.7 to 6.7$)$. Predictably, this effect increases with severity of conflict.

These new estimates of the mortality burden are important given that the accuracy of commonly-cited crude estimates of maternal (and possibly child) deaths in such settings has been criticised. ${ }^{3}$ However, these new mortality figures do not capture the lasting impact that exposure to violence in war and conflict has on the mental health and developmental trajectories of children ${ }^{4-6}$ or the thousands of childhoods lost through conscription of child soldiers ${ }^{78}$ or through sexual and gender based violence in such settings. ${ }^{9}$ Over half of all refugees are children, and in 2017 alone, 173800 unaccompanied and separated child refugees and asylum seekers were reported worldwide. ${ }^{10}$ Many of these children were victims of violence. ${ }^{11}$

We still lack the knowledge and tools required to effectively restore, protect, and promote the health and wellbeing of women and children affected by conflict. We know which health interventions and services work in development settings, and often how best to implement them, but our understanding and appreciation of what more can be done for women and children affected by conflict remains limited.

Guidelines and guidance on prioritising and implementing child health and nutrition interventions in conflict settings remain sparse. ${ }^{12}$ Existing handbooks and manuals are constrained by a general focus on broader humanitarian settings or by a paucity of evidence to underpin or inform maternal and child health recommendations. ${ }^{13}$ Armed conflict poses specific difficulties for implementation of health interventions, especially the complex and dynamic challenges to security and governance. We must learn more about how best to reach women and children caught up in conflict and how best to provide them with optimal care.

Fortunately, primary research in this area is growing. Multiple funding initiatives now explicitly support rigorous, ethical testing of strategies for delivering child focused interventions in conflict settings. However, new research findings must be interpreted in relation to the whole body of evidence, ideally collated through systematic reviews.

Later this year, BMJ journals will publish a series of systematic reviews by the BRANCH Consortium (Bridging Research and Action in Conflict Settings for the Health of Women and Children) that synthesise what the existing literature can and cannot tell us about delivering health and nutrition interventions to women and children in the context of armed conflict.

These reviews complement other BRANCH work on critical assessment of existing guidelines and guidance for tackling reproductive, maternal, newborn, child, and adolescent health and nutrition in conflict settings, in addition to mixed-methods studies of coordination, decision making, and health service delivery among humanitarian actors in 10 countries affected by conflict. We hope that the systematic reviews, along with complementary articles published elsewhere, will amplify the urgent need and global call for better evidence, better care, and better outcomes for children and their families affected by conflict.

Competing interests: We have read and understood BMJ policy on declaration of interests and declare that the authors are recipients of funding granted to the BRANCH Consortium from the Norwegian Agency for Development Cooperation, the Bill \& Melinda Gates Foundation, the International Development Research Centre, the Family Larsson-Rosenquist Foundation, Unicef, and the Partnership for Maternal, Newborn, and Child Health.

Provenance and peer review: Commissioned; not externally peer reviewed.

Save the Children International. The war on children: time to end grave violations against children in conflict. 2018. https://www.savethechildren.org/content/dam/global/reports/ education-and-child-protection/war_on_children-web.pdf 
2 Wagner Z, Heft-Neal S, Bhutta ZA, Black RE, Burke M, Bendavid E. Armed conflict and child mortality in Africa: a geospatial analysis. Lancet 2018;392:857-65. 10.1016/S0140-6736(18)31437-5 30173907

3 Nordenstedt $\mathrm{H}$, Rosling $\mathrm{H}$. Chasing $60 \%$ of maternal deaths in the post-fact era. Lance 2016;388:1864-5. 10.1016/S0140-6736(16)31793-7 27751384

4 Kadir A, Shenoda S, Goldhagen J. Effects of armed conflict on child health and development: a systematic review. PLoS One 2019;14:e0210071. 10.1371/journal pone.021007130650095

5 Bhutta ZA. Children of war: the real casualties of the Afghan conflict. BMJ2002;324:349-52. 10.1136/bmj.324.7333.349 11834566

6 Punamäki RL, Diab SY, Isosävi S, Kuittinen S, Qouta SR. Maternal pre- and postnatal mental health and infant development in war conditions: the Gaza Infant Study. Psychol Trauma 2018;10:144-53. 10.1037/tra0000275 28406660

7 Roos H, Böhmelt T. Child soldiers as time bombs? Adolescents' participation in rebel groups and the recurrence of armed conflict. Eur $\mathrm{J}$ Int Relat 2016:22:408-3610.1177/1354066115581910

8 Machel G. Impact of armed conflict on children: report of the expert of the secretary-general. 1996. http://www.un.org/ga/search/view_doc.asp?symbol-=A/51/306\& Lang $=E \& A r e a=U N D O C$
9 Wirtz AL, Perrin NA, Desgroppes A, etal . Lifetime prevalence, correlates and health consequences of gender-based violence victimisation and perpetration among men and women in Somalia. BMJ Glob Health 2018:3:e000773.

10.1136/bmjgh-2018-000773 30105094

10 UNHCR. Global trends: forced displacement in 2017. https://www.unhcr.org/globaltrends2017

11 Sawyer CB, Márquez J. Senseless violence against Central American unaccompanied minors: historical background and call for help. J Psychol 2017;151:69-75. 10.1080/00223980.2016.122674327660898

12 Frison S, Smith J, Blanchet K. Does the humanitarian sector use evidence-informed standards? a review of the 2011 sphere indicators for wash, food security and nutrition, and health action. PLOS Curr

2018;10:ecurrents.dis.40805a591152be1c1431b5dab43e516d.

10.1371/currents.dis.40805a591152be1c1431b5dab43e516d. 30443433

13 Singh NS, Smith J, Aryasinghe S, Khosla R, Say L, Blanchet K. Evaluating the

effectiveness of sexual and reproductive health services during humanitarian crises: a systematic review. PLoS One 2018;13:e0199300. 10.1371/journal.pone.0199300 29980147

Published by the BMJ Publishing Group Limited. For permission to use (where not already granted under a licence) please go to http://group.bmj.com/group/rights-licensing/ permissions 